\title{
Biochemical and molecular diagnosis of erythropoietic protoporphyria in an Ashkenazi Jewish family
}

\author{
X. Schneider-Yin • R. Mamet • \\ E. I. Minder • N. Schoenfeld
}

Received: 1 April 2008/Submitted in revised form: 28 May 2008 / Accepted: 4 June 2008 / Published online: 31 August 2008

(C) SSIEM and Springer 2008

\begin{abstract}
Summary Erythropoietic protoporphyria (EPP) is a rare hereditary disorder due to a partial deficiency of ferrochelatase $(\mathrm{FECH})$. The genotype of EPP patients features a mutation on one allele of the $F E C H$ gene and a common hypomorphic FECH IVS3-48c on the other allele $(\mathrm{M} / \mathrm{c})$. The resulting enzyme activity in patients is $\sim 35 \%$ of that in normal individuals. Ferrochelatase deficiency results in the accumulation of protoporphyrin in the skin, which is responsible for the clinical symptom of cutaneous photosensitivity in patients. In this study, we report the identification of a novel FECH mutation delT23 in an 11-member EPP
\end{abstract}

Communicating editor: Georg Hoffmann

Competing interests: None declared

References to electronic databases: OMIM: http://www.ncbi. nlm.nih.gov/Omim/. Gen Bank: http://www.ncbi.nlm.nih.gov/ GenBank/ (for human FECH cDNA [NM000140], human FECH gene [NT025028], human FECH protein [NP000131]). Human Gene Mutation Database (HGMD): http://www. archive.uwcm.ac.uk/uwcm/mg/hgmd0.html/. Erythropoietic protoporphyria: OMIM \#177000). Ferrochelatase: EC 4.99.1.1.

X. Schneider-Yin · E. I. Minder ( $\bowtie)$

Zentrallabor, Stadtspital Triemli,

Birmensdorferstrasse 497,

CH-8063 Zürich, Switzerland

e-mail: elisabeth.minder@triemli.stzh.ch

R. Mamet $\cdot$ N. Schoenfeld

National Laboratory for the Biochemical Diagnoses

of Porphyrias, Rabin Medical Center, Beilinson Hospital,

Petah-Tikva, Israel

N. Schoenfeld

Department of Human Molecular Genetics

and Biochemistry, The Sackler Faculty of Medicine,

Tel Aviv University, Tel Aviv, Israel family of Jewish origin. Two EPP siblings shared an identical genotype of delT23/IVS3-48c (M/c). They were both photosensitive and showed highly increased erythrocyte protoporphyrin. The genotype of the patients' mother, who did not present with any EPP clinical symptoms, was delT23/IVS3-48t (M/t). The patients' father, an offspring of consanguineous parents, was homozygous IVS3-48 c/c. He exhibited a mild photosensitivity, and an increase of 4-fold in erythrocyte protoporphyrin. His FECH mRNA amount was $71 \%$ of that of genotype $t / t$. It is the first reported case of an individual with c/c genotype who exhibits both biochemical and clinical indications of EPP. These results suggest that IVS3-48c is a functional variant of ferrochelatase. The clinical symptoms and biochemical abnormalities in the patients' father could be the result of an interaction between genetic and environmental factors. In addition, the frequency of IVS3-48c in the Ashkenazi Jewish population was estimated at $8 \%$, which is similar to that in the European populations.

$\begin{array}{ll}\text { Abbreviations } \\ \text { EPP } & \text { erythropoietic protoporphyria } \\ \text { FECH } & \text { ferrochelatase } \\ \text { PCR } & \text { polymerase chain reaction } \\ \text { RBC } & \text { red blood cells } \\ \text { SNP } & \text { single nucleotide polymorphism }\end{array}$

\section{Introduction}

Erythropoietic protoporphyria (EPP, OMIM \#177000) is a hereditary disorder of the haem biosynthetic pathway. The affected enzyme ferrochelatase $(\mathrm{FECH}$, 
EC 4.99.1.1) catalyses the insertion of iron into protoporphyrin IX to form haem. As the result of ferrochelatase deficiency, a large amount of protoporphyrin accumulates in the skin, which is responsible for the clinical symptoms of photosensitivity in EPP patients (Anderson et al 2001). In addition to the cutaneous symptoms, EPP-related liver failure occurs in about $1 \%$ of the patients (Holme et al 2006). EPP is transmitted as an autosomal dominant trait in $>97 \%$ of the cases, or as an autosomal recessive trait. In the dominant inheritance, which occurs in the majority of the families, the clinical expression of EPP requires a deleterious mutation on one allele of the FECH gene and a common SNP IVS3-48c on the other allele $(\mathrm{M} / \mathrm{c})$. The frequencies of IVS3-48c vary from population to population. The highest frequency found so far, $45 \%$, was in the Japanese population and the lowest, less than 1\%, among black Africans (Gouya et al 2006; Nakano et al 2006).

To date, a total of 109 mutations have been described in the FECH gene of EPP families (HGMD, accessed in March 2008). In this study, we report biochemical and genetic characterization of EPP in an Ashkenazi Jewish family in which the father was an offspring of consanguineous parents.

\section{Material and methods}

Subjects and biochemical analyses

An 11-member Ashkenazi family of three generations was studied (Fig. 1). The index patient, a 36-year-old woman and her 26-year-old brother, have suffered from skin photosensitivity since early childhood. They were diagnosed as EPP patients at the ages of 24 and 14 years, respectively. The diagnosis was established in both on the basis of highly increased erythrocyte protoporphyrin and a distinct peak in the plasma emission scan at $635 \mathrm{~nm}$ (Table 1). As shown in the table, both exhibited increased faecal protoporphyrin. Normal faecal coproporphyrin (15 and $25 \mu \mathrm{g} / \mathrm{g}$ dry weight, respectively) and a ratio of 0.3 of coproporphyrin III/I (normal <1) were measured in both of them (not shown). So far, the patients have exhibited normal liver function. The father of the index patient, who was an offspring of consanguineous parents, suffered from mild symptoms of photosensitivity. $\mathrm{He}$ experienced a feeling of itching and burning in the skin shortly after sun exposure. He has tried to avoid the sun throughout his life. Repeated measurements showed 3- to 4-fold increases in erythrocyte protoporphyrin concentration. A slight increase in erythrocyte protoporphyrin concentration was observed also in the mother as well as in the eldest son of the index patient (Table 1). The rest of the family members were not tested biochemically. None of them showed clinical signs of EPP.

Fifty non-porphyric individuals of Jewish origin (Ashkenazi), three non-porphyric caucasians with genotypes $\mathrm{t} / \mathrm{t}, \mathrm{c} / \mathrm{t}$ and $\mathrm{c} / \mathrm{c}$ at IVS3-48 in the $F E C H$ gene, respectively, as well as an EPP patient from an unrelated family (genotype $\mathrm{M} / \mathrm{c}$ ), were recruited into the study. Informed consent was obtained from all subjects. This study was approved by the Helsinki committee of the Israeli Ministry of Health.

Plasma fluorescence emission scanning was carried out according to Long et al (1993). Erythrocyte free

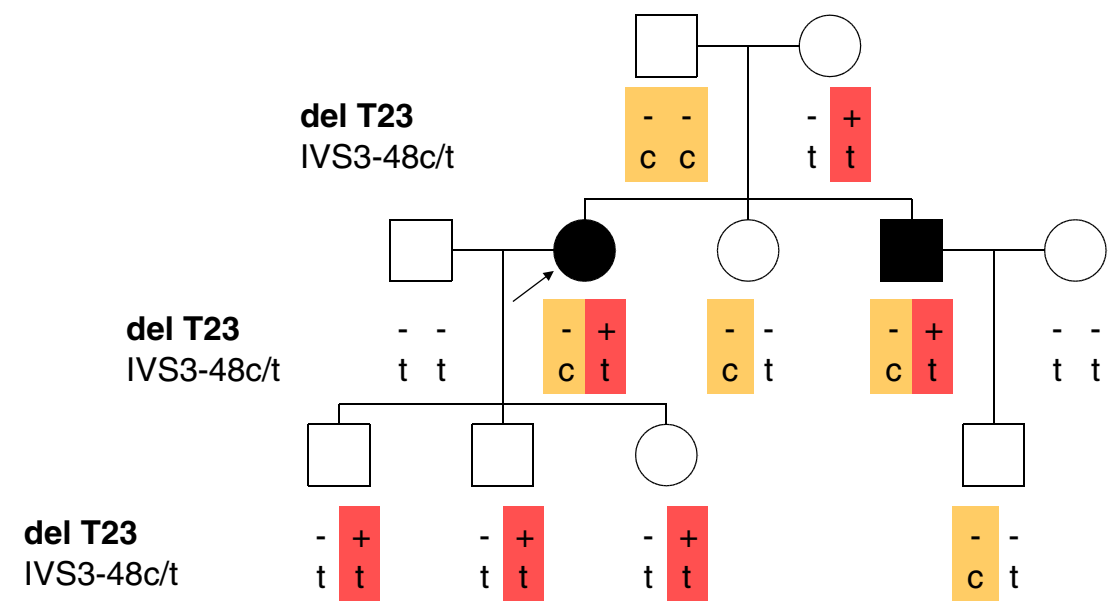

Fig. 1 Pedigree of an Ashkenazi EPP family. Solid symbols represent EPP patients with the genotype $\mathrm{M} / \mathrm{c}$ and the open symbols represent individuals with genotype $\mathrm{M} / \mathrm{t}$. The index patient is indicated by an arrow. The $F E C H$ alleles are illustrated

below the symbol of each individual. The mutated allele is highlighted in red and the low-expressed allele (IVS3-48c) in orange. wt, wild type; M, mutation delT23. The presence/absence of mutation $\operatorname{del}$ T23 is indicated by ' $+/-$ ' 
Table 1 Clinical and biochemical data from the Israeli EPP family

\begin{tabular}{|c|c|c|c|c|c|c|c|}
\hline Subjects & $\begin{array}{l}\text { Age } \\
\text { (years) }\end{array}$ & Photosensitivity & $\begin{array}{l}\text { Erythrocyte } \\
\text { protoporphyrin } \\
(<80 \mu \mathrm{g} / \mathrm{dl} \mathrm{RBC})\end{array}$ & $\begin{array}{l}\text { Plasma } \\
\text { fluorescence } \\
\text { peak }(\mathrm{mm})^{\mathrm{a}}\end{array}$ & $\begin{array}{l}\text { Faecal protoporphyrin } \\
\text { (<80 } \mu \mathrm{g} / \mathrm{g} \text { dry weight) }\end{array}$ & $\begin{array}{l}\text { Mutation } \\
\text { delT23 }\end{array}$ & $\begin{array}{l}\text { SNP } \\
\text { IVS3-48c/t }\end{array}$ \\
\hline Index $^{b}$ & 36 & +++ & 4917 & 188 & 680 & Present & $\mathrm{c} / \mathrm{t}$ \\
\hline Brother $^{b}$ & 26 & +++ & 6684 & 128 & 1072 & Present & $\mathrm{c} / \mathrm{t}$ \\
\hline Father & 58 & + & 338 & 2 & $<80$ & Absent & $\mathrm{c} / \mathrm{c}$ \\
\hline Mother & 58 & - & 133 & 4 & $<80$ & Present & $t / t$ \\
\hline Sister & 33 & - & 70 & None & $<80$ & Absent & $\mathrm{c} / \mathrm{t}$ \\
\hline Eldest son & 9 & - & 160 & 3 & n.d. & Present & $\mathrm{t} / \mathrm{t}$ \\
\hline
\end{tabular}

n.d.: not determined.

${ }^{a}$ Height of the peak in the emission scan, observed at wavelengths $404 \mathrm{~nm}$ (excitation) and $635 \mathrm{~nm}$ (emission).

${ }^{\mathrm{b}}$ Biochemical analyses were carried out at the time of diagnosis.

protoporphyrin was measured according to the method of Piomelli (1973), modified as previously described (Schoenfeld et al 2003). Faecal porphyrins were extracted according to With (1978) and separated by HPLC according to Lim and Peters (1984).

Mutational analysis

Peripheral blood samples were collected from all subjects. Genomic DNA was isolated from peripheral blood using the QIAamp Blood Kit (Qiagen, Hilden, Germany). The 11 coding exons of the FECH gene, along with 52-191 bp of their flanking regions, were amplified by PCR using specific primers. Sequence analysis was performed on the ABI Prism 310 genetic analyser (Applied Biosystems, Foster City, CA, USA). Sequence analysis of genomic DNA also revealed the status of SNP IVS3-48c/t in the subjects.

\section{Preparation of cDNA}

For preparation of cDNA, a separate blood sample was collected from the subjects concerned in a PAXgene Blood RNA tube (Qiagen). Total RNA was isolated by using the PAXgene Blood RNA Validation Kit (Qiagen). An aliquot of total RNA was analysed on an Agilent 2100 Bioanalyzer (Agilent, Palo Alto, CA, USA) using the Eukaryote Total RNA Nano Kit. The quality of total RNA was evaluated by both the $28 \mathrm{~S} / 18 \mathrm{~S}$ ratio and RIN (RNA integrity number). mRNA (1 $\mu \mathrm{g}$ of total RNA) was reverse-transcribed into cDNA by using the First Strand cDNA Synthesis Kit (Roche, Basel, Switzerland).

\section{Real-time PCR quantification of FECH cDNA}

Real-time PCR quantification of ferrochelatase cDNA was performed on an ABI Prism 7000 Sequence
Detection System (Applied Biosystems). $\beta$-Actin was used as an endogenous control. Reagents used for realtime PCR were all purchased from Applied Biosystems. PCR conditions, i.e. reaction mixture and temperature profile, were according to the manufacturer's recommendations. The relative amount of FECH mRNA was calculated as previously described (Aurizi et al 2007).

Genotyping using microsatellite markers

Genotype analysis was conducted in the father of the index patient using 10 microsatellite markers. These markers are located in the genomic region of the FECH gene in the order of cen-D18S69-D18S1152D 18S 41 - D 18 S 858 - FE CH-D 18S381 - D 18 S 977 D18S1144-D18S1129-D18S1155-D18S64-qter in the LDB map (Collins et al 1996). Fluorescence-labelled PCR primers were synthesized with the available sequence information. PCR was carried out using standard conditions. Fragment length analysis was performed on the ABI Prism 310 genetic analyser (Applied Biosystems).

\section{Results}

Mutational analysis was initiated in the index patient. Direct sequencing of PCR-amplified FECH gene fragments identified a single nucleotide $\mathrm{T}$ deletion at cDNA position 23 in the first exon (delT23). Frameshift, as the result of the deletion, generates a premature stop codon at amino acid position 72. The rest of the family members were screened specifically for the delT23 mutation. The result showed that besides the index patient, five other individuals including her brother, her mother and all three of her children also carried the mutation. No mutation was 
Table 2 Levels of FECH mRNA in various individuals

\begin{tabular}{lll}
\hline Subjects & $\begin{array}{l}\text { SNP } \\
\text { IVS3-48c/t }\end{array}$ & $\begin{array}{l}\text { Amount of normal FECH } \\
\text { transcript in relation to that } \\
\text { in control 1 (defined as 100\%) }\end{array}$ \\
\hline Control 1 & $\mathrm{t} / \mathrm{t}$ & 100 \\
Control 2 & $\mathrm{c} / \mathrm{t}$ & 93 \\
Control 3 & $\mathrm{c} / \mathrm{c}$ & 64 \\
Father of the & $\mathrm{c} / \mathrm{c}$ & 71 \\
index patient & & 32 \\
An unrelated & $\mathrm{M} / \mathrm{c}$ & 31 \\
EPP patient & & \\
\hline
\end{tabular}

found in the entire $F E C H$ gene of the patients' father by sequencing. Mutation delT23 was also absent in the FECH gene of 50 non-porphyric Ashkenazi subjects.

SNP IVS3-48c/t was analysed among all the members of the family. The segregation pattern between mutation delT23 and SNP IVS3-48c/t within the family is depicted in Fig. 1. Genotyping of SNP IVS3-48 among 50 non-porphyric Ashkenazi control subjects identified 42 homozygotes IVS3-48t/t and 8 heterozygotes IVS3-48c/t. The frequency of IVS3-48c is therefore estimated as $8 \%$ in this population.

The father of the index patient was homozygous IVS3-48c/c, a rare genotype in the general population. The homozygosity was mostly likely due to the parental consanguinity. Besides IVS3-48c/c, he was homozygous for other intragenic SNPs including IVS1-23t/t, 287G/G, 798C/C, 921G/G, IVS10-61g/g. The results of microsatellite analysis extended the homozygosity to a distance of at least $7.4 \mathrm{cM}$ flanking the FECH gene.

To test the presence of diploid $F E C H$ alleles in the patients' father, FECH mRNA was quantified by realtime PCR and compared with that of control subjects (genotypes $\mathrm{t} / \mathrm{t}, \mathrm{c} / \mathrm{t}$ and $\mathrm{c} / \mathrm{c}$ ), as well as that of an EPP patient from an unrelated family (genotype $\mathrm{M} / \mathrm{c}$ ). As shown in Table 2, the relative amount of $\mathrm{FECH}$ mRNA decreases in the order of $t / t, c / t, c / c$ and $M / c$. The value obtained from the father of the index patient was $71 \%$ that of control 1 (genotype $t / t$ ), which is comparable with $64 \%$ measured in control 3 (genotype c/c). However, control 3 was non-porphyric.

\section{Discussion}

EPP cases have been described in various populations. The family of this study however, is the second genetically tested EPP family ever reported in Israel (Schoenfeld et al 2003). Extensive biochemical analyses were conducted among members of this family prior to genetic testing. The clinical and the biochemical evidences, which included cutaneous photosensitivity in combination with immense increases of protoporphyrin concentration in erythrocytes as well as presence of fluorescence peaks at $635 \mathrm{~nm}$, was sufficient to ascertain an EPP diagnosis in the index patient and her brother. Interestingly, both of their parents also presented with abnormal erythrocyte protoporphyrin concentrations, i.e. a 4-fold increase in the father and a 1.7-fold increase in the mother, and measurable peaks in the plasma scan (Table 1). In addition, the father was slightly photosensitive. These findings raised the question whether EPP is recessive in this family.

At the genetic level, the identification of a single mutation delT23 and the characterization of SNP IVS3-48c/t in the FECH gene proved the dominant form of EPP in the family. As shown in Fig. 1, both patients have an identical genotype of a mutated FECH allele in trans to a low-expressed FECH allele featuring IVS3-48c (M/c). This genotype, according to Gouya et al, is required for the clinically overt EPP which is the result of a reduction of the overall enzyme activity below a critical threshold of $\sim 35 \%$, assuming that the allele in which the frameshift mutation delT23 is resided will not produce any active enzyme (Gouya et al 2006). The delT23 mutation apparently originated from the patients' mother. She, as well as three of her grandchildren, had the genotype of a mutated allele in trans to a normal FECH allele (M/t). According to the current knowledge, these four individuals will remain asymptomatic throughout their lives because of the $50 \%$ of normal amount of ferrochelatase enzyme they possess.

A more complex situation was found in the patients' father. Clinically, he presented with only a mild

Table 3 Frequency of low-expressed FECH allele (IVS3-48c) among different populations

\begin{tabular}{lcl}
\hline Population & Frequency & Source \\
\hline Japanese & $45 \%$ & Nakano et al (2006) \\
Chinese (Han) & $41 \%$ & Kong et al (2008) \\
Southeast Asian & $31 \%$ & Gouya et al (2006) \\
British & $13 \%$ & Berroeta et al (2007) \\
French & $11 \%$ & Gouya et al (2006) \\
Jewish & $\mathbf{8 \%}$ & This study \\
$\quad$ (Ashkenazi) & & \\
Swiss & $7 \%$ & Schneider-Yin and Minder, \\
& & unpublished data \\
Spanish & $5 \%$ & Herrero et al (2007) \\
North African & $3 \%$ & Gouya et al (2006) \\
Italian & $1 \%$ & Aurizi et al (2007) \\
Black West Africa & $<1 \%$ & Gouya et al (2006) \\
\hline
\end{tabular}


photosensitivity. Biochemically, a substantial increase in protoporphyrin concentration was repeatedly measured in erythrocytes. At the genetic level, no mutations were identified in his $F E C H$ gene apart from the homozygosity of IVS3-48c. His FECH mRNA was $71 \%$ of that of control 1 who has the genotype $t / t$.

The mild photosensitivity presented by the patients' father could be attributed to the increased erythrocyte protoporphyrin concentration, a phenomenon which was shown in one of our previous studies (Cohen et al 2005). However, at the present time, the cause(s) of increased protoporphyrin concentration in this particular individual is not fully understood. The FECH gene, or IVS3-48c in that sense, is likely to play a role in this setting. Although homozygous $\mathrm{c} / \mathrm{c}$ alone might not be sufficient, additional factors, genetic and environmental alike, might act together to give rise to the clinical and biochemical abnormalities in this individual.

This study has shown that a combination of a disabling FECH mutation with the hypomorphic $F E C H$ IVS3-48c was the cause of EPP in two members of the Jewish family. The $8 \%$ prevalence of IVS3-48c in the Ashkenazi Jewish population is similar to that found in the European populations (Table 3). More importantly, this study presented the first case of an individual with c/c genotype who had both clinical and biochemical indications of EPP. These observations suggest that IVS3-48c is a functional variant of ferrochelatase and thus plays a role in the pathogenesis of EPP.

Acknowledgements We would like to express our gratitude to all members of the family for their participation in the study. We would like to thank Sulejman Ahmetovic, Zürich, Switzerland, for his excellent technical assistance.

\section{References}

Anderson K, Sassa S, Bishop D, Desnick R (2001) Disorders of heme biosynthesis: X-linked sideroblastic anemia and the porphyrias. In: Scriver CR, Beaudet AL, Sly WS, Valle D, eds; Childs B, Kinzler KW, Vogelstein B, assoc. eds. The Metabolic and Molecular Bases of Inherited Disease, 8th edn. New York: McGraw-Hill, 2991-3062.

Aurizi C, Schneider-Yin X, Sorge F, Macri A, Minder EI, Biolcati G (2007) Heterogeneity of mutations in the ferrochelatase gene in Italian patients with erythropoietic protoporphyria. Mol Genet Metab 90: 402-407. doi:10.1016/ j.ymgme.2006.10.012.

Berroeta L, Man I, Goudie DR, Whatley SD, Elder GH, Ibbotson SH (2007) Late presentation of erythropoietic protoporphyria: case report and genetic analysis of family members. Br J Dermatol 157: 1030-1031. doi:10.1111/j.13652133.2007.08117.x.

Cohen AD, Mermershtain W, Geffen D, et al (2005) Cutaneous photosensitivity induced by paclitaxel and trastuzumab therapy associated with aberrations in the biosynthesis of porphyrins. J Dermatolog Treat 16: 19-21. doi:10.1080/ 09546630510026724.

Collins A, Frezal J, Teague J, Morton NE (1996) A metric map of humans: 23,500 loci in 850 bands. Proc Natl Acad Sci U S A 93: 14771-14775. doi:10.1073/pnas.93.25.14771.

Gouya L, Martin-Schmitt C, Robreau AM, et al (2006) Contribution of a common single-nucleotide polymorphism to the genetic predisposition for erythropoietic protoporphyria. Am J Hum Genet 78: 2-14. doi:10.1086/498620.

Herrero C, To-Figueras J, Badenas C, et al (2007) Clinical, biochemical, and genetic study of 11 patients with erythropoietic protoporphyria including one with homozygous disease. Arch Dermatol 143: 1125-1129. doi:10.1001/ archderm.143.9.1125.

Holme SA, Anstey AV, Finlay AY, Elder GH, Badminton MN (2006) Erythropoietic protoporphyria in the U.K.: clinical features and effect on quality of life. $B r J$ Dermatol 155: 574-581. doi:10.1111/j.1365-2133.2006.07472.x.

Kong XF, Ye J, Gao DY, et al (2008) Identification of a ferrochelatase mutation in a Chinese family with erythropoietic protoporphyria. J Hepatol 48: 375-379. doi:10.1016/ j.jhep.2007.09.013.

Lim CK and Peters TJ (1984), Urine and faecal porphyrin profiles by reversed-phase performance liquid chromatography in the porphyrias. Clin Chim Acta 139: 55-63. doi:10.1016/ 0009-8981(84)90192-X.

Long C, Smith S, Woolf J, et al (1993) Detection of latent variegate porphyria by fluorescence emission spectroscopy of plasma. Br J Dermatol 129: 9-13. doi:10.1111/j.13652133.1993.tb03303.x.

Nakano H, Nakano A, Toyomaki Y, et al (2006) Novel ferrochelatase mutations in Japanese patients with erythropoietic protoporphyria: high frequency of the splice site modulator IVS3-48C polymorphism in the Japanese population. J Invest Dermatol 126: 2717-2719. doi:10.1038/sj.jid. 5700456.

Piomelli S (1973) Micromethod for free erythrocytes porphyrin: the FEP test. J Lab Clin Med 81: 932-940.

Schoenfeld N, Mamet R, Minder EI, Schneider-Yin X (2003) A "null allele" mutation is responsible for erythropoietic protoporphyria in an Israeli patient who underwent liver transplantation: relationships among biochemical, clinical, and genetic parameters. Blood Cells Mol Dis 30: 298-301. doi:10.1016/S1079-9796(03)00040-8.

With TK (1978) Clinical porphyrin analysis: indications and interpretations. Scand J Clin Lab Invest 38: 501-505. doi:10.3109/ 00365517809108811. 